\title{
Habitat selection and the conservation status of Fischer's turaco Tauraco fischeri on Unguja, Tanzania
}

\author{
Luca Borghesio and Paul Kariuki Ndang'ang'a
}

\begin{abstract}
We report the results of a survey of Fischer's turaco Tauraco fischeri in Unguja (otherwise known as Zanzibar). We estimated the species' range, population size and habitat selection using unlimited distance point counts. The main results are: 1) Fischer's turaco is more widely distributed in the coral rag zone than previously thought, with an area of occupancy estimated at $56 \mathrm{~km}^{2}$, 2) the species does not occur in agricultural habitats and tree plantations, 3) within natural habitats it selects places with denser tree cover, 4) food availability does not differ between occupied and unoccupied sites, and 5) the turaco population on Unguja was estimated at c. 1,400 individuals. Only $44 \%$ of the population is in protected areas, and habitat degradation is occurring at a high rate. Only $16 \%$ of the habitat occupied by Fischer's turaco on the island has low signs of human impact.
\end{abstract}

\section{Introduction}

Turacos are a distinctive group of birds endemic to tropical Africa. They are shy, frugivorous and live in forests or dense woodland habitats, descending to ground only occasionally in order to bathe or drink (Fry et al., 1988; Turner, 1997). Their presence is often familiar to ornithologists, as they utter raucous calls that can be heard hundreds of meters away. All the 14 species presently recognized (Turner, 1997) have light green plumages, with blue wings, erectile crests, striking crimson flight feathers and a distinctive facial ornamentation. Although they are popular as cage birds, there is little information on most aspects of their ecology. Two species in the genus (Tauraco ruspolii and T. bannermani) are presently categorized as globally threatened (IUCN, 2002), but due to the rapid loss of forest cover in Africa several other species could be decreasing in number (Turner, 1997). However, without reliable population estimates and information on any population trends, assessment of conservation status is problematical.

Luca Borghesio ${ }^{1}$ (Corresponding author) and Paul Kariuki Ndang'ang'a Department of Ornithology, National Museums of Kenya, P.O. Box 40658 Nairobi, Kenya. E-mail: borghesio@libero.it

${ }^{1}$ Present address: C. Re Umberto 42, I-10128 Torino, Italy.

Received 28 September 2002. Revision requested 16 January 2003 Accepted 19 June 2003.
Present levels of exploitation of natural habitats on Unguja appear to be unsustainable and it seems likely that all unprotected forests on the island will be lost within a few years. The range of Fischer's turaco is highly fragmented and the population is likely to be decreasing. This turaco was often observed in places where other threatened species were also present, suggesting that it could be both a flagship and an umbrella species for the implementation of wider habitat conservation strategies. The conservation status of Fischer's turaco should be reconsidered, with its IUCN threatcategory upgraded from Lower Concern: near threatened to Vulnerable.

Keywords Fragmentation, habitat selection, population estimate, Red List, Tauraco fischeri, Unguja, Zanzibar.
Fischer's turaco ( $T$. fischeri) is restricted to the coast of southern Somalia, Kenya and northern Tanzania. It is currently categorized as Lower Risk: near threatened (IUCN, 2002), but Turner (1997) suggested that its status may be in need of re-evaluation. This is particularly urgent for the subspecies endemic to the island of Unguja ( $T$. fischeri zanzibaricus), otherwise known as Zanzibar, which is only known from Jozani, a small forest reserve in the southern part of the island. Following its description in the 1930s (Pakenham, 1938) the subspecies was observed only rarely, and was even rumoured to be extinct (Britton, 1980).

There is a scarcity of biological information for most of the biota of Unguja, which has received little scientific attention in the past. This may, in part, be due to its relatively recent separation from the mainland (Kingdon, 1989) and thus to a perceived low level of endemism. However, the island is now known to have several endemic or near-endemic mammals (Kingdon, 1997) and butterflies (Kielland \& Cordeiro, 2000). The importance of Unguja for conservation is high, as the main natural habitat on the island, the Eastern African coastal forest, is well known for its biological richness and is highly threatened (Burgess \& Clarke, 2000). In June and July 2001 we conducted a survey of Fischer's turaco on Unguja. Our aim was to describe the species' habitat and assess its present and likely future conservation status. 


\section{Study area}

Unguja is located in the southern Indian Ocean, $40 \mathrm{~km}$ off the coast of Tanzania. The island has an area of c. $1,666 \mathrm{~km}^{2}$ (Department of Statistics, 1999) and can be divided into two zones with different soil types (Fig. 1).
The deep soil or plantation area, in the western part of the island, supports permanent cultivation, while the coral rag zone, where shallow soils lie above a bed of coralline reef limestone, can only support shifting cultivation and annual crops. As environmental conditions in the densely inhabited deep-soil zone are incompatible with
Fig. 1 Unguja island, with the inset indicating its position off the coast of Tanzania. The deep-soil area in the western part of the island is represented with barred hatching. Areas in black were totally deforested between 1977-78 and 2001, areas in medium grey those where forest cover was maintained, and areas in light grey those where vegetation regrowth occurred. Unshaded areas have been modified by man for grazing, cultivation and other activities. The broken line indicates the approximate borders of Jozani Forest Reserve.

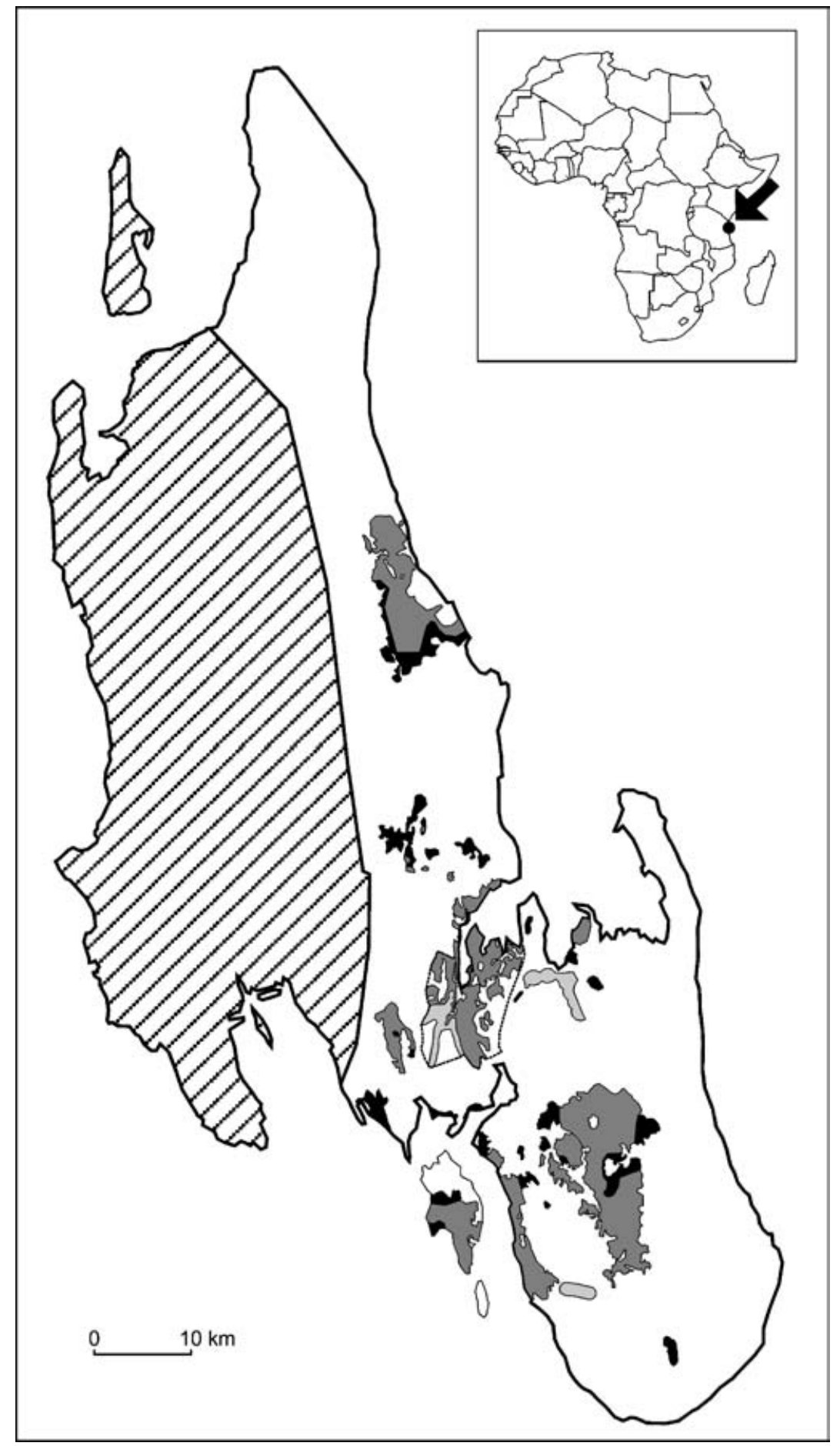


the presence of turacos, this study was confined to the coral rag zone. This area is mostly covered by natural vegetation, from low bushland to high forest, most of it secondary in nature as it is normally cut for shifting agriculture, with fallow periods of 20-25 years (Masoud, 1993). However, some forests appear to have had substantially longer fallow periods of up to 100 years (Williams et al., 1996). Within the study area we recognized three main habitat types (Fig. 1):

Man modified. This includes open grassland, probably fire-induced, used for grazing livestock, tree plantations (coconut, mango and oranges or wood-producing trees, mostly Casuarina equisetifolia), cultivation (mostly cassava) and settled areas.

Albizia-dominated. This vegetation type is usually found along the coast. The most characteristic trees are Albizia glaberrima, A. adianthifolia and A. gummifera. Albizia-dominated vegetation can develop naturally from abandoned fields, which are initially invaded by shrubs (Mallotus oppositifolius is common in the early stages) and finally develop into a forest with a canopy at $\geq 20 \mathrm{~m}$ and sparse undergrowth. However, these forests are often subjected to logging, which removes most of the large and medium-sized trees, opening the canopy and allowing the growth of a dense shrub layer. We included with this habitat the small area of ground-water forest, entirely contained within Jozani Forest Reserve and dominated by screw palm Pandanus rabaiensis and oil palm Elaeis guineensis. It was not possible to investigate this habitat separately because of its small area (probably c. 200 ha) and inaccessibility.

Diospyros-dominated. This vegetation occurs in drier areas or on shallower soils than the Albizia-dominated community. Diospyros consolatae is ubiquitous; other common tree species are Rapanea melanophloeos, Mystroxylon aethiopicum, Olea woodiana, Euclea schimperi and E. racemosa. Diospyros-dominated vegetation can develop on abandoned fields, which are initially invaded by fast-growing shrubs and small trees, such as Psiadia arabica and Dodonaea viscosa. The final stage is a forest-like formation, but with a lower canopy than that formed by Albizia, with trees rarely taller than $15 \mathrm{~m}$, a continuous canopy and little undergrowth. On the whole, this vegetation type is the most common in the study area, although in most cases human activity has reduced the forest to 2-3 $\mathrm{m}$ tall bushland.

\section{Methods}

\section{Bird survey}

From 22 June to 21 July 2001 we censused Fischer's turaco by unlimited-distance point counts (Bibby et al.,
2000), which were carried out at all times of the day. At each point we played records (supplied by the National Sound Archive of the British Library) of song and calls of the species to elicit the response of birds. Census points were evenly spaced (at distances of $700 \mathrm{~m}$ when moving by car, and $400 \mathrm{~m}$ when bicycles were used) along the trails that cut into the vegetation of the coral rag zone. The location of each survey point was recorded with a Global Positioning System (GPS). Recordings were played for 15 minutes, and all turacos heard or seen during this period were counted. The distance from the observer to the birds was measured either by pacing, range-finder or GPS; comparison of these different techniques indicated good measurement repeatability. In each census point we also recorded visual or vocal contacts with four other species: an introduced pest, the Indian house crow Corvus splendens, two Endangered mammals, the Zanzibar red colobus Procolobus kirkii and black-and-rufous elephant shrew Rhynchocyon petersi, and the widespread Syke's monkey Cercopithecus mitis.

\section{Habitat data}

We assessed habitat characteristics by recording 12 variables (Table 1 ) in a sample of 181 census points (48 in the Albizia-dominated and 133 in the Diospyrosdominated habitat). Human impact was estimated in 208 plots (all those where habitat characteristics were recorded, plus an additional 27 plots) by counting the number of cut or damaged woody stems within a $10 \mathrm{~m}$ radius of the observer. A mean value of this measure was obtained for each of the eight zones where Fischer's turaco presence was confirmed (Fig. 2) and categorized into 3 classes $(0-5$ stems per plot $=$ class 1 , low impact; $5-20=$ class 2 , medium impact; $>20=$ class 3 , high impact).

All distances were measured with a range-finder. Canopy leaf density was measured with a canopy scope (Brown et al., 2000) on a scale ranging from 0 (maximum canopy density) to 25 (maximum openness). Fruit and flower abundance were scored visually $(0=$ none, $1=$ few and mostly unripe, 2 = abundant, $3=$ very abundant and ripe). Undergrowth vegetation density was estimated by measuring the distance of $50 \%$ disappearance of a chequered-board $(40 * 40 \mathrm{~cm})$ held at $1.5 \mathrm{~m}$ above the ground; greater distances indicated sparser undergrowth. We defined a tree as any woody plant taller than $3 \mathrm{~m}$. At the points where a turaco was contacted, habitat variables were measured in a plot centred on the point where the bird was observed, otherwise they were recorded in a randomly located plot within $50 \mathrm{~m}$ of the census point. 
Table 1 Description of habitat variables, including the abbreviations used in the text, the units in which each variable was recorded, and the radius of the area assessed for their measurement.

\begin{tabular}{|c|c|c|c|}
\hline Variable & Abbreviation & Units & $\begin{array}{l}\text { Radius } \\
\text { of area } \\
\text { assessed }(\mathrm{m})\end{array}$ \\
\hline Fruit abundance & FRUIT & score $(0-3)$ & 25 \\
\hline Flowers abundance & FLOWER & score $(0-3)$ & 25 \\
\hline Vegetation cover between 0 and $1 \mathrm{~m}$ & $\%$ GRASS & $\%$ & 25 \\
\hline Vegetation cover between 1 and $3 \mathrm{~m}$ & $\%$ SHRUB & $\%$ & 25 \\
\hline Vegetation cover between 3 and $8 \mathrm{~m}$ & \%LOWTREE & $\%$ & 25 \\
\hline Vegetation cover above $8 \mathrm{~m}$ & \%HIGHTREE & $\%$ & 25 \\
\hline Number of trees with $\mathrm{dbh}^{*}<5 \mathrm{~cm}$ & TREE0-5 & $n$ & 10 \\
\hline Number of trees with dbh $5-20 \mathrm{~cm}$ & TREE5-20 & $n$ & 10 \\
\hline Number of trees with $\mathrm{dbh}>20 \mathrm{~cm}$ & TREE $>20$ & $n$ & 10 \\
\hline Canopy height (average of 3 measures) & CANHT & $\mathrm{m}$ & 10 \\
\hline Canopy leaf density (average of 3 measures with canopy scope) & OPENNESS & score $(0-25)$ & 10 \\
\hline $50 \%$ disappearance of a $40 * 40 \mathrm{~cm}$ chequered board held at $1.5 \mathrm{~m}$ height (average of 3 measures) & CHQBOARD & $\mathrm{m}$ & \\
\hline
\end{tabular}

*dbh, diameter at breast height

\section{Data analysis}

\section{Habitat selection}

We described the habitat of Fischer's turaco by comparing occupied sites to those where the bird was not found. We used a one-way ANOVA for studying habitat variables that could be normalized by appropriate transformations (percentages were arcsine- and counts $\log (x+1)$-transformed). Variables that could not satisfy the assumptions of parametric tests were studied with Mann-Whitney U tests.

\section{Estimation of range and evaluation of habitat conservation status}

We prepared an approximated map of forest cover (Fig. 1) in the coral rag zone by digitizing habitat features from 1:10,000 maps based on aerial photographs of 1977-78 (Directorate of Overseas Surveys, 1983). Because forest cover on Unguja decreased dramatically between 1977 and 2001, we updated the habitat map during the field work by taking numerous ( $>400$ ) fixes with a GPS and recording the presence of forest at each point. We then plotted on the updated map all the points where the presence of Fischer's turaco was confirmed. We joined these points into clusters having the following characteristics: all points located in a continuous patch of the same habitat, or the edge of the habitat patch was formed by clear discontinuities in the vegetation (usually the transition from natural forest to man-modified habitat or low bush). Alternatively, when discontinuities were not clear and habitat changed gradually (this occurred only in Diospyros-dominated vegetation), the edge was drawn at a distance equal to the mean distance between the points enclosed in the cluster.
To evaluate the effects of human activity on habitat structure, we compared (with a one-way ANOVA) the average values of 10 structural habitat variables (all those listed in Table 1, except FRUIT and FLOWER) between plots classified in the three human impact classes. One variable (TREE $>20$ ) that could not be normalized was analysed with the Kruskal-Wallis test, a non-parametric equivalent of one-way ANOVA.

\section{Population estimates}

We estimated total population size by fitting a detection function to the data and deriving a density estimate from it. This procedure can account for individuals that remained unseen, provided that the detection probability at the centre of the census area is $100 \%$ (Buckland et al., 1993). The function was fitted using the computer software Distance 3.5 (Thomas et al., 1998), and the performance of the different models was evaluated using the Akaike Information Criterion (AIC; Akaike, 1973), assuming that the model that minimized AIC was the one that best fits the data. Within the complete data set we selected the 136 point counts that were made within the range of the species (Fig. 2) in order to derive density estimates within habitats occupied by Fischer's turaco. Distances of the individuals from the census point were grouped into two classes (0-120 and 121-240 m). We chose to group the data into only two bands because we suspected that turacos near the observation point could be attracted towards it by the playback of their calls, therefore inflating estimates (Bibby et al., 2000). By lumping all observations in only two distance bands, overestimation was limited only to those birds that moved from the farthest to the nearest band. Our field experience suggests that these were a minor fraction of the total. 


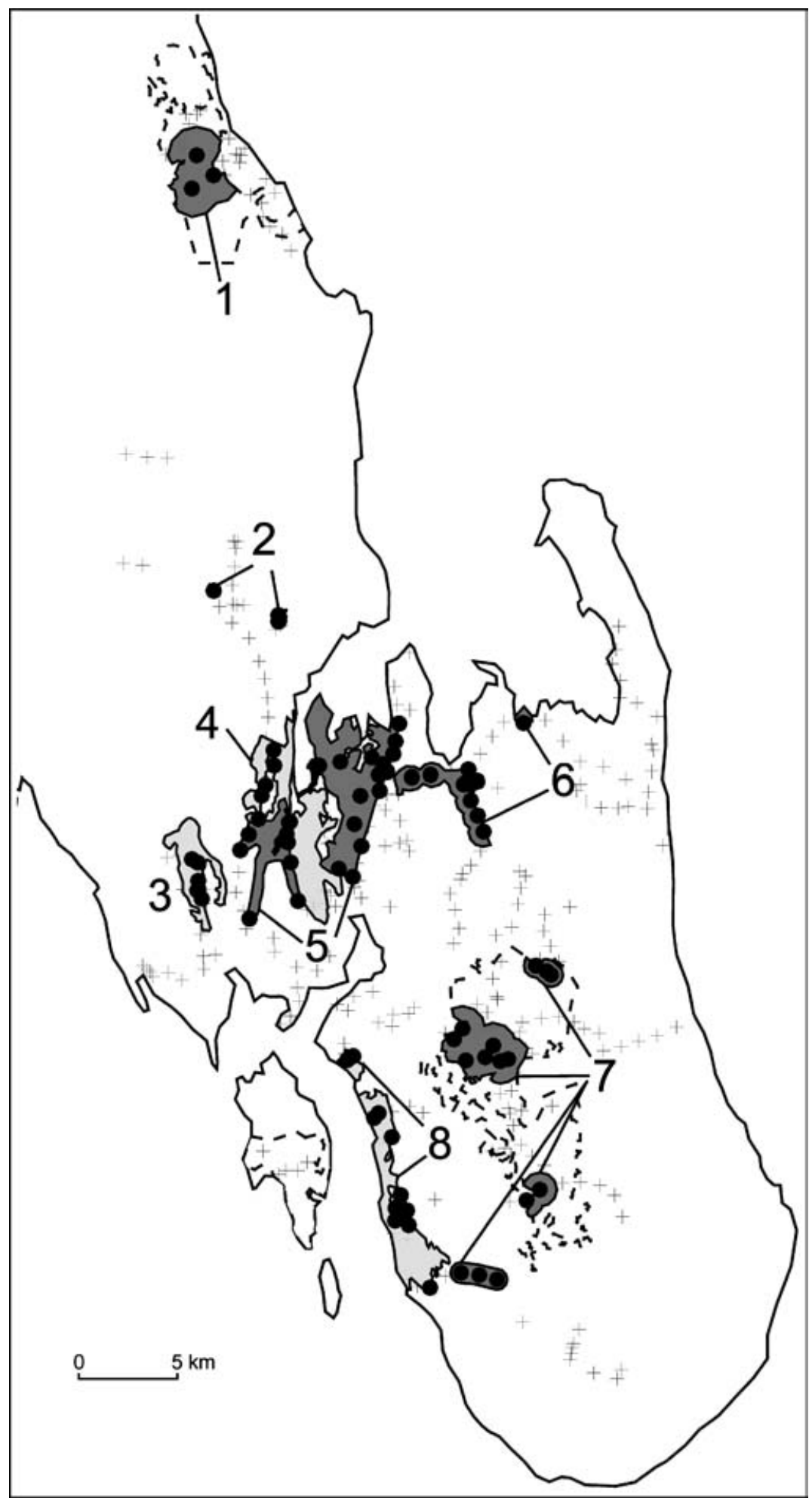

Fig. 2 Estimated range of Fischer's turaco. Light grey patches are Albizia-dominated habitat, and dark grey Diospyros-dominated (see text for details). The southern part of area 4 (locality Jozani A of Table 4) is partly occupied by ground-water forest (see text for details). Black circles are points were the presence of Fischer's turaco was confirmed, and crosses mark the other census points. The broken line delimits existing natural woodland with trees $>5 \mathrm{~m}$ high on average, but where turacos were apparently absent; these areas are all in the highest humanimpact class (see text for further details). Numbers identify the forest areas of Table 4.

As we often observed turacos in groups of $2-5$, but group size could not be recorded for those individuals that were only heard, we estimated group size by averaging the number of individuals seen within a range of $100 \mathrm{~m}$ from the observation point. This estimate
(1.4 individuals) was then used as the mean group size for density calculation. Separate density estimates were produced for Albizia-dominated and Diospyros-dominated habitats. Variances were calculated using 999 bootstrap iterations. 
Other vertebrates in the census points

Chi-squared tests with one degree of freedom were used to determine if Fischer's turaco co-occurred with other species more or less often than expected.

\section{Results}

\section{Habitat selection}

Altogether 325 different points were sampled within the coral rag zone. Fischer's turaco presence was confirmed at 76 points (Fig. 2), all within Albizia or Diospyrosdominated habitat (Table 2). Fischer's turaco was more or less continuously distributed in Albizia vegetation, and were observed in each of 10 days of field work in this

Table 2 Number of points visited within the three habitat categories, and the number and percentage of points at which Fischer's turaco was recorded.

\begin{tabular}{lcll}
\hline Habitat type & $\begin{array}{l}\text { No of } \\
\text { census } \\
\text { points }\end{array}$ & $\begin{array}{l}\text { No of } \\
\text { points with } \\
\text { T.fischeri }\end{array}$ & $\begin{array}{l}\text { \% of } \\
\text { points with } \\
\text { T.fischeri }\end{array}$ \\
\hline Man-modified & 27 & 0 & 0.0 \\
Albizia-dominated & 58 & 29 & 50.0 \\
Diospyros-dominated & 240 & 47 & 19.6 \\
\hline
\end{tabular}

habitat. In Diospyros-dominated habitat, Fischer's turaco was encountered much less frequently and apparently patchily. This was evident in zones 1 and 7 (Fig. 2), where it occupied only a fraction of a larger area of homogeneous vegetation (outlined by the broken line in Fig. 2).

Sites occupied by turacos in Albizia-dominated habitat had more vegetation cover $>3 \mathrm{~m}$ in height, more trees $<20 \mathrm{~cm}$ of diameter, and a higher and more closed canopy compared to sites where the species was not found (Table 3). In Diospyros-dominated habitat, occupied sites differed from unoccupied ones by features similar to those of importance in Albizia-dominated habitat, except that a greater density of trees with diameter $>20 \mathrm{~cm}$ was observed. In both habitats fruit and flower abundance did not differ significantly among sites with or without turacos (Table 3).

\section{Range and habitat conservation status}

In 1977-78 the area of the island covered by high trees was $115.1 \mathrm{~km}^{2}\left(41.3 \mathrm{~km}^{2}\right.$ of Albizia and $73.8 \mathrm{~km}^{2}$ of Diospyros-dominated habitat, Fig. 1). The range of Fischer's turaco in 2001 was entirely in areas already forested in 1977-78, except for three patches of Diospyros $\left(8.7 \mathrm{~km}^{2}\right.$ in total; light grey areas in Fig. 1). These patches may

Table 3 Summary of the 12 habitat variables (see Table 1) in places occupied and unoccupied by Fischer's Turaco. Differences were tested with a one-way ANOVA ( $F$ statistic) or Mann-Whitney $U$ test (see text for details).

\begin{tabular}{|c|c|c|c|c|c|}
\hline Habitat type & Variable & Test statistic & $\mathrm{P}^{*}$ & $\begin{array}{l}\text { Average value } \\
\text { (turaco absent) }\end{array}$ & $\begin{array}{l}\text { Average value } \\
\text { (turaco present) }\end{array}$ \\
\hline \multirow[t]{12}{*}{ Albizia-dominated } & FRUIT & $U=194$ & 0.160 & 1.4 & 1.3 \\
\hline & FLOWER & $U=226.5$ & 0.500 & 1.2 & 0.9 \\
\hline & $\%$ GRASS & $F_{1,44}=0.98$ & 0.330 & 45.0 & 40.5 \\
\hline & $\%$ SHRUB & $F_{1,44}=0.80$ & 0.270 & 55.8 & 52.1 \\
\hline & \%LOWTREE & $F_{1,44}=11.71$ & 0.001 & 45.0 & 59.0 \\
\hline & \%HIGHTREE & $F_{1,44}=21.83$ & $<0.001$ & 15.2 & 35.0 \\
\hline & TREE0-5 & $F_{1,44}=5.86$ & 0.019 & 29.7 & 41.4 \\
\hline & TREE5-20 & $F_{1,44}=32.20$ & $<0.001$ & 6.1 & 14.9 \\
\hline & TREE $>20$ & $U=211$ & 0.300 & 2.1 & 2.5 \\
\hline & CANHT & $F_{1,44}=5.27$ & 0.027 & 7.9 & 9.6 \\
\hline & OPENNESS & $F_{1,44}=4.67$ & 0.036 & 10.1 & 7.6 \\
\hline & CHQBOARD & $F_{1,44}=0.65$ & 0.056 & 5.4 & 6.5 \\
\hline \multirow[t]{12}{*}{ Diospyros-dominated } & FRUIT & $U=1638.5$ & 0.180 & 1.2 & 1.4 \\
\hline & FLOWER & $U=1589.5$ & 0.110 & 0.9 & 0.8 \\
\hline & $\%$ GRASS & $F_{1,129}=0.41$ & 0.520 & 45.2 & 42.8 \\
\hline & $\%$ SHRUB & $F_{1,129}=0.28$ & 0.590 & 63.6 & 63.5 \\
\hline & \%LOWTREE & $F_{1,129}=15.28$ & $<0.001$ & 44.9 & 56.4 \\
\hline & \%HIGHTREE & $F_{1,129}=5.08$ & 0.026 & 5.5 & 12.0 \\
\hline & TREE0-5 & $F_{1,129}=2.06$ & 0.150 & 48.5 & 56.5 \\
\hline & TREE5-20 & $F_{1,129}=9.99$ & 0.002 & 9.0 & 12.0 \\
\hline & TREE $>20$ & $U=1225.5$ & $<0.001$ & 0.6 & 1.4 \\
\hline & CANHT & $F_{1,129}=15.66$ & $<0.001$ & 4.7 & 6.0 \\
\hline & OPENNESS & $F_{1,129}=8.21$ & 0.005 & 13.7 & 10.1 \\
\hline & CHQBOARD & $F_{1,129}=1.81$ & 0.180 & 5.2 & 5.4 \\
\hline
\end{tabular}

*Probability levels $<0.05$ are in bold. 
be new habitat created by natural regrowth. Between 1977-78 and 2001 at least $24.8 \mathrm{~km}^{2}$ (10.5 of Albizia- and $14.3 \mathrm{~km}^{2}$ of Diospyros-dominated habitat) were deforested (Fig. 1). Taking into account the possible regrowth in some areas, the net loss of wooded habitats amounted to $16.1 \mathrm{~km}^{2}$, i.e. total forest area was reduced to $99.0 \mathrm{~km}^{2}$ in 2001.

The range occupied by Fischer's turaco in 2001 amounted to $55.8 \mathrm{~km}^{2}$, of which $34.1 \mathrm{~km}^{2}$ were Diospyrosdominated and $21.7 \mathrm{~km}^{2}$ Albizia-dominated (Table 4). Of the total estimated range, $24.7 \mathrm{~km}^{2}$ ( $44.3 \%$ of total area) is presently under some form of protection (Table 4). Overall, $23.1 \mathrm{~km}^{2}$ (41.4\%) of Fischer's turaco range is in human-impact class $3,23.5 \mathrm{~km}^{2}(42.1 \%)$ in class 2 and $9.2 \mathrm{~km}^{2}(16.5 \%)$ in class 1 (Table 4$)$. All the patches with human-impact 1 , and most $(60.4 \%)$ of those with impact 2 are inside Jozani Forest Reserve. All the wooded areas where Fischer's turaco was not found $\left(43.2 \mathrm{~km}^{2}\right.$ of Diospyros-dominated habitat, marked by the broken line in Fig. 2) were in human-impact class 3.

Human impact had marked effects on vegetation structure. In both habitats eight of the 10 vegetation structural variables showed significant variations (Table 5). In higher human impact areas we found a higher cover of shrubs, a lower tree cover, especially in the highest strata, a lower density of woody stems, and a lower

Table 4 Characteristics of those areas where Fischer's Turaco presence was observed, including human-impact class (see text for details). The area numbers correspond to those in Figure 2.

\begin{tabular}{|c|c|c|c|c|c|}
\hline Area no. & Locality & Habitat type & Area $\left(\mathrm{km}^{2}\right)$ & Present protection & $\begin{array}{l}\text { Human- } \\
\text { impact class }\end{array}$ \\
\hline 1 & Kiwengwa & Diospyros & 5.6 & Proposed forest reserve & 3 \\
\hline 2 & Chwaka fragments & Albizia & 0.3 & Used by local people as a prayer place & 2 \\
\hline 3 & Cheju & Albizia & 4.0 & None & 2 \\
\hline 4 & Jozani A & Albizia & 9.2 & Most of the area is a forest reserve & 1 \\
\hline 5 & Jozani B & Diospyros & 15.2 & Most of the area is a forest reserve & 2 \\
\hline 6 & Ukongoroni & Diospyros & 4.0 & None & 2 \\
\hline 7 & Muyuni interior & Diospyros & 9.6 & None & 3 \\
\hline 8 & Muyuni coast & Albizia & 7.9 & None & 3 \\
\hline
\end{tabular}

Table 5 Average value of the 12 habitat variables (see Table 1) in Alibizia- and Diospyros-dominated habitats and in places with different levels of human impact. Differences were tested with a one-way ANOVA (F statistic) or the Kruskal-Wallis test ( $H$ statistic; see text for details).

\begin{tabular}{|c|c|c|c|c|c|c|}
\hline \multirow[b]{2}{*}{ Variable } & \multirow[b]{2}{*}{ Habitat type } & \multicolumn{3}{|c|}{ Average value of variable in plots } & \multirow[b]{2}{*}{ Test statistic } & \multirow[b]{2}{*}{$\mathrm{P}^{*}$} \\
\hline & & $\begin{array}{l}\text { Human impact } \\
1 \text { (low) }\end{array}$ & $\begin{array}{l}\text { Human impact } \\
2 \text { (medium) }\end{array}$ & $\begin{array}{l}\text { Human impact } \\
3 \text { (high) }\end{array}$ & & \\
\hline \multirow[t]{2}{*}{$\%$ GRASS } & Albizia & 33.9 & 40.5 & 49.6 & $F_{2,45}=2.4$ & 0.100 \\
\hline & Diospyros & 38.2 & 36.2 & 43.0 & $F_{2,130}=0.9$ & 0.390 \\
\hline \multirow[t]{2}{*}{ \%SHRUB } & Albizia & 37.8 & 54.0 & 58.8 & $F_{2,45}=5.9$ & 0.010 \\
\hline & Diospyros & 57.9 & 59.2 & 63.2 & $F_{2,130}=1.1$ & 0.350 \\
\hline \multirow[t]{2}{*}{ \%LOWTREE } & Albizia & 63.9 & 59.0 & 49.6 & $F_{2,45}=3.0$ & 0.060 \\
\hline & Diospyros & 62.9 & 53.1 & 52.7 & $F_{2,130}=3.4$ & 0.040 \\
\hline \multirow[t]{2}{*}{ \%HIGHTREE } & Albizia & 47.8 & 33.0 & 19.7 & $F_{2,45}=14.1$ & $<0.001$ \\
\hline & Diospyros & 26.7 & 13.0 & 5.9 & $F_{2,130}=4.5$ & 0.010 \\
\hline \multirow[t]{2}{*}{ TREE0-5 } & Albizia & 45.4 & 41.2 & 33.4 & $F_{2,45}=0.4$ & 0.670 \\
\hline & Diospyros & 65.0 & 54.7 & 55.4 & $F_{2,130}=1.6$ & 0.210 \\
\hline \multirow[t]{2}{*}{ TREE5-20 } & Albizia & 20.9 & 9.4 & 9.6 & $F_{2,45}=7.5$ & 0.001 \\
\hline & Diospyros & 16.7 & 12.0 & 10.6 & $F_{2,130}=4.0$ & 0.020 \\
\hline \multirow[t]{2}{*}{ TREE $>20$} & Albizia & 3.2 & 3.4 & 1.5 & $H_{2,130}=21.2$ & $<0.001$ \\
\hline & Diospyros & 1.9 & 1.4 & 0.9 & $H_{2,45}=5.0$ & 0.080 \\
\hline \multirow[t]{2}{*}{ CANHT } & Albizia & 11.9 & 10.1 & 7.5 & $F_{2,45}=11.6$ & $<0.001$ \\
\hline & Diospyros & 7.8 & 6.2 & 5.3 & $F_{2,129}=4.8$ & 0.010 \\
\hline \multirow[t]{2}{*}{ OPENNESS } & Albizia & 3.7 & 7.0 & 10.6 & $F_{2,45}=9.2$ & $<0.001$ \\
\hline & Diospyros & 8.0 & 9.2 & 11.4 & $F_{2,130}=2.9$ & 0.060 \\
\hline \multirow[t]{2}{*}{ CQBOARD } & Albizia & 8.9 & 5.2 & 5.4 & $F_{2,45}=8.7$ & $<0.001$ \\
\hline & Diospyros & 6.6 & 6.4 & 4.7 & $F_{2,130}=3.1$ & 0.050 \\
\hline
\end{tabular}

*Probabilities < 0.05 are in bold. 
mean canopy height. In Diospyros-dominated habitat, Fischer's turaco was recorded more frequently at points with human-impact class 1 or $2\left(\chi_{1,157}^{2}=3.9, \mathrm{P}=0.05\right)$, but in Albizia-dominated habitat there was no difference in frequency of observations between the three human-impact classes $\left(\chi_{1,51}^{2}=0.02, \mathrm{P}=0.90\right)$.

\section{Population estimates}

The detection function that best fitted the data, according to the AIC, contained a uniform function with a simple polynomial series expansion. The model estimated a total population of 1,419 , with a density of $0.25 \mathrm{ha}^{-1}$ of suitable habitat (Table 6). Mean population density was similar in Albizia-dominated and Diospyros-dominated habitats. However, Diospyros, the more common habitat type, had a higher proportion $(61 \%)$ of the total population. Only $44 \%$ (530 individuals) of the total population was estimated to be within protected areas.

\section{Other vertebrates in the census points}

The presence of Fischer's turaco was significantly correlated with that of the other 4 species. The correlation was positive with Zanzibar red colobus $\left(\chi_{1,325}^{2}=16.1\right.$, $\mathrm{P}=0.0001)$, black-and-rufous elephant-shrew $\left(\chi_{1,325}^{2}=7.0\right.$, $\mathrm{P}=0.008)$ and Syke's monkey $\left(\chi_{1,325}^{2}=13.8, \mathrm{P}=0.0004\right)$, but not with Indian house crows $\left(\chi_{1,325}^{2}=11.9, \mathrm{P}=0.001\right)$.

\section{Discussion}

This study is the first to focus on the biology and conservation of Fischer's turaco. Previous published observations of this species on Unguja are few (Pakenham, 1979; Turner, 1997), and are all restricted to the area around Jozani forest. Our study showed, however, that Fischer's turaco is more widely distributed in the island. Although it is possible that further surveys may locate other subpopulations, especially in the central part of Unguja or on the small island of Uzi to the south-west (Fig. 2), our survey has provided a detailed account of the status of the species. The current distribution pattern

Table 6 Population density and estimates of total numbers of Fischer's Turaco within the two main habitat types, Albizia- and Diospyros-dominated.

\begin{tabular}{|c|c|c|}
\hline Habitat type & $\begin{array}{l}\text { Density as birds ha } \\
\text { (95\% confidence interval) }\end{array}$ & $\begin{array}{l}\text { No of birds } \\
\text { (95\% confidence } \\
\text { interval) }\end{array}$ \\
\hline Pooled & $0.25(0.20-0.33)$ & $1,419(1,089-1,808)$ \\
\hline Albizia & $0.25(0.18-0.35)$ & $552(397-750)$ \\
\hline Diospyros & $0.26(0.19-0.35)$ & 867 (640-1150) \\
\hline
\end{tabular}

indicates a shrinking and increasingly fragmented range, with the nucleus in Jozani Forest.

Fischer's turaco avoids heavily man-modified habitats such as agricultural fields and tree plantations. Thus, it seems less adaptable than other turaco species, which on mainland Africa often occur in man-modified habitats (Turner, 1997). Fischer's turaco selects two different habitat types: Albizia- and Diospyros-dominated forests and thickets. It preferred similar features in both habitats, with its occurrence being positively associated with increasing tree density. More specifically, we found that sites with turacos had more tree cover, a higher density of tree stems, and higher and more closed canopies than sites lacking turacos. On the other hand, fruit availability did not differ between occupied and unoccupied sites, suggesting that the species' distribution on Unguja is limited by habitat availability rather than food abundance. The presence of turacos was more discontinuous and fragmented in Diospyros-dominated habitats, where we found wide expanses of apparently unoccupied areas. Moreover, census points classified as impact class 3 (high impact) were occupied less frequently in Diospyrosdominated, but not in Albizia-dominated habitats. This suggests that Albizia could be the preferred habitat of the species, as there it can withstand more physical habitat disturbance than in Diospyros.

Our estimate of c. 1,400 individuals on Unguja is higher than the 100 estimated by Turner (1997). This is in part due to our larger sampling area. However, it is also likely that the secretive behaviour of the species led to underestimation of its presence and abundance and to the earlier claim of possible extinction (Britton, 1980). The main findings of our study are that the range and the total population of Fischer's turaco on Unguja are larger than previously thought. However, the species is sensitive to habitat quality, avoiding highly manmodified habitats, and even within 'natural' woodland it prefers more densely vegetated areas. We suggest that the existence (Fig. 2) of large expanses of habitat lacking turacos can be explained by the high human impact in these areas. Thus, deforestation and habitat degradation seem to be the major threats to the species.

During the last 30 years, the human population of Unguja has been growing at $>3 \%$ per annum (Department of Statistics, 1999). As the needs of the people have been steadily increasing, there has been a progressive movement of people from the overcrowded plantation areas to the coral rag zone. Although the clearing of land for agriculture has been extensive, it appears that habitat degradation due to firewood collection, charcoal production and timber extraction has been much more widespread; presently almost all wooded areas outside Jozani are under intense exploitation. We found that most of the natural woodland or forest outside Jozani 
is in human-impact class 3, which had a strongly reduced tree density. Moreover, deforestation between 1977-78 and 2001 affected $>20 \%$ of total forest area. The comparison of our data with that of Beentje (1990) also shows that many forests have been cleared or severely degraded over the last decade. This poses the question of how the needs of the local human population could be satisfied in the future. We doubt that it will be possible to maintain the integrity of the small protected areas when they become the only remaining sources of wood. At the present level of exploitation it is likely that within a few years no natural forest will remain outside protected areas. As $56 \%$ of the estimated population of Fischer's turaco on the island lives outside reserves, a major population decrease is to be expected in the future.

Fischer's turacos were often observed along with other species of high conservation concern. It seems likely that the foreseen population decrease of $>50 \%$ for the turaco will also affect the other threatened species of Unguja. These decreases and the restriction of the residual populations to few areas could trigger an extinction crisis on the island and actions need to be taken to avoid this. We suggest two priorities:

Firstly, conservation efforts up to now have focused on a single area, Jozani Forest Reserve. However, substantial populations of other endemic and threatened taxa live outside the reserve. It is important that the scope of future actions is widened to encompass a larger area. The forests in the southern part of the island (zones 7 and 8 of Fig. 2) are in particular need of protection.

Secondly, the main reason for woodland degradation is firewood extraction. Although woodcutters are required to pay fees for felling trees, these are rarely exacted. This means that wood taken from natural forests is presently more or less free of cost. The enforcement of existing laws demanding the payment of fees for extracting wood from public lands could make it economically less profitable to exploit natural forests. This could encourage the creation of tree plantations on land presently occupied by young secondary habitats of little conservation value. At the same time, more attention should be focused on different sources of fuel (such as gas) or more efficient ways of using firewood (such as stoves).

Unguja still holds a considerable wealth of natural resources that attracts many tourists, themselves an important source of income. However, practically all tourist interest focuses on the red colobus in Jozani. Fischer's turaco, being a species of considerable beauty and rarity, has potential for attracting interest from birdwatchers and for generating revenue. Moreover, our finding that Fischer's turaco is not only found in Jozani could be of help in raising awareness for other areas requiring protection. On the whole, Fischer's turaco has both the characteristics of a flagship and an umbrella species: i.e. it is both a charismatic species that could provide focus for conservation awareness and, at the same time, it has habitat requirements such that, if adequately protected, would ensure the protection of other threatened species. The potential value of the turaco as a flagship species is of particular interest as it has been suggested that local attitudes should be of primary importance in the selection of such species (Bowen-Jones \& Entwistle, 2002). While attitudes towards the red colobus have become increasingly negative, as the species is erroneously perceived as a crop pest (Siex \& Struhsaker, 1999), local people usually have a positive attitude toward turacos because of their beautiful plumage. Fischer's turaco also fits well in the criteria suggested by Bowen-Jones \& Entwistle (2002), as it is a locally endemic subspecies (thus providing a possible symbol of local allegiance) and it is well-known and not readily confused with other species.

The categorization of Fischer's turaco as Lower Risk: near-threatened (IUCN, 2002) requires reassessment. We suggest that it should be categorized as Vulnerable under the IUCN Red List criteria (IUCN/SSC, 1994) as it qualifies under criterion A2c, i.e. population reduction of at least $20 \%$ suspected to occur within the next 10 years based on decline in area of occupancy, extent of occurrence and quality of habitat.

\section{Acknowledgements}

The project was initiated by Conservation des Espèces et des Populations Animales (CEPA, France). Funding was provided by CEPA, International Touraco Society (ITS), UK, Zoologische Gesellschaft für Artenund Populationsschutz, Germany, Parc Zoologique et Botanique de Mulhouse, France, and the BENELUX branch of ITS. The support of these sponsors is gratefully appreciated: Mohammed Ayoub Haji, Aliy Abdurahim Aliy, Marcy Edwards, Danica Demilio, Andrea Borghesio and Roberto Gavioso took part in the field work. Thanks are due to Thabit Masoud and Ali Basha of the Department of Commercial Crops, Fruits and Forestry, Zanzibar, for providing technical advice. Mario Mariani, Don Turner and Silvia Ceppi also gave assistance and help. Kirstin Siex and Paola Laiolo gave useful suggestions for improving the paper.

\section{References}

Akaike, H. (1973) Information theory and an extension of the maximum likelihood principle. In International Symposium on Information Theory, 2nd edition (eds B.N. Petran \& F. Csàaki), pp. 267-281. Akadèemiai Kiadi, Budapest, Hungary. 
Beentje, H.J. (1990) A reconnaissance survey of Zanzibar forests and coastal thicket. Zanzibar Environmental Study Series, 7, $1-34$

Bibby, C.J., Burgess, N.D., Hill, D.A. \& Mustoe, S.H. (2000) Bird census techniques. Academic Press, London, UK.

Bowen-Jones, E. \& Entwistle, A. (2002) Identifying appropriate flagship species: the importance of culture and local contexts. Oryx, 36, 189-195.

Britton, P.L. (ed.) (1980) Birds of East Africa, their Habitat, Status and Distribution. East Africa Natural History Society, Nairobi, Kenya.

Brown, N., Jennings, S., Wheeler, P. \& Nabe-Nielsen, J. (2000) An improved method for the rapid assessment of forest light environments. Journal of Applied Ecology, 37, 1044-1053.

Buckland, S.T., Anderson, D.R., Burnham K.P. \& Laake, J.L. (1993) Distance Sampling. Estimating Abundance of Biological Populations. Chapman and Hall, London, UK.

Burgess, N.D. \& Clarke, P.G. (2000) Coastal Forests of Eastern Africa. IUCN, Gland, Switzerland and Cambridge, UK.

Department of Statistics (1999) Zanzibar Statistical Abstract, 1997. Department of Statistics, Zanzibar, Tanzania.

Directorate of Overseas Surveys (1983) 1:10,000 Zanzibar Map. Department of Lands and Surveys, Zanzibar, Tanzania.

Fry, C.H., Keith, S. \& Urban, E.K. (1988) The Birds of Africa, Volume 3. Academic Press, London, UK.

IUCN (2002) 2002 IUCN Red List of Threatened Species. IUCN, Gland, Switzerland [http:/ /www.redlist.org, accessed 21 January 2003].

IUCN/SSC (1994) IUCN Red Data List Categories. IUCN Species Survival Commission, Gland, Switzerland.

Kielland, J. \& Cordeiro, N.J. (2000) Butterflies. In Coastal Forests of Eastern Africa (eds N.D. Burgess \& P.G.Clarke), pp. 225-233. IUCN, Gland, Switzerland and Cambridge, UK. Kingdon, J. (1989) Island Africa. Princeton University Press, Princeton, USA.

Kingdon, J. (1997) The Kingdon Field Guide to African Mammals. Academic Press, London, UK.
Masoud, R.S. (1993) Fuelwood use in Zanzibar town. Zanzibar Forestry Development Project Technical Paper, 3, 1-36.

Pakenham, R.H.W. (1938) A new race of Turacus. Bulletin of the British Ornithologist's Club, 58, 111-112.

Pakenham, R.H.W. (1979) The Birds of Zanzibar and Pemba. British Ornithologists Union Checklist No. 2, UK.

Siex, K.S. \& Struhsaker, T.T. (1999) Colobus monkey and coconuts: a study of perceived human-wildlife conflicts. Journal of Applied Ecology, 36, 1009-1020.

Thomas, L., Laake, J.L., Derry, J.F., Buckland, S.T., Borchers, D.L., Anderson, D.R., Burnham, K.P., Strindberg, S., Hedley, S.L., Burt, M.L., Marques, F.F.C., Pollard, J.H. \& Fewster, R. M. (1998) Distance 3.5. Research Unit for Wildlife Population Assessment, University of St. Andrews, UK.

Turner, D.A. (1997) Musophagidae. In Handbook of the Birds of the World, Volume 4 (eds J. Del Hoyo, A. Elliott \& J. Sargatal), pp. 480-506. Lynx Edicions, Spain.

Williams, A., Mwinyi, A.A. \& Said, J.A. (1996) A population survey of the mini-antelope of Unguja. Zanzibar Subcommission for Forestry Technical Paper, 27, 1-160.

\section{Biographical sketches}

Luca Borghesio has been carrying out ornithological research in Italy and East Africa for the last 10 years. His main research interests are bird and insect community ecology and conservation.

Kariuki Ndang'ang'a is mainly involved in bird research in forests and grasslands. He has also been working for the Important Bird Areas Programme in Kenya, and in the development of Action Plans for globally-threatened birds. 